\title{
Congenital aural atresia surgery: anterior mastoid and transmastoid approaches
}

\author{
Essam Fathy Mohammed(D)
}

\begin{abstract}
Background: Aural atresia (CAA) is a congenital abnormality with hypoplasia or aplasia of the external auditory canal. Surgical procedures of CAA is not only difficult but has still not been embraced by surgeons. Many surgeons are doubtful to perform a repair due to poor hearing results and the risk of new canal stenosis. This article describes the writers' expertise with surgical management of aural atresia. A retrospective study of 16 cases of CAA was undertaken in the Hearing and Speech Institute between 2015 and 2018. The study consisted of 16 patients, 8 patients for each group, 10 males and 6 females between 4 and 18 years of age with a median age of 6 years. Ten patients had bilateral atresia, and 6 had unilateral atresia. Postoperatively, patients were tested for hearing recovery and follow-up lasting up to 2 years to record any complications. Purpose of the study was to compare hearing effects and risks of anterior and transmastoid approaches to external and middle ear restoration in patients with CAA.
\end{abstract}

Results: All patients were satisfied with the surgery by improving the hearing up to $35 \mathrm{~dB}$ or less after 12 months. Four patients (25\%) developed soft tissue meatal stenosis, with 2 patients in each group. There were no cases of bony canal stenosis. TM perforation was seen in two patients (12.51\%), one patient in each group. Lateralization of the graft was seen in one patient in the transmastoid group, and no ossicular chain refixation. Five cases had postoperative otorrhea, one in the anterior mastoid group and four in the transmastoid group. There were no other complications.

Conclusions: Although the findings of the hearing are close. The previous approach, due to fewer postoperative complications, is now our favorite technique. Proper alignment and soft-tissue strategies are keys to the effective correction of the congenitally atretic ear canal.

Keywords: Aural atresia, Hearing outcomes, Surgery, Anterior approach, Transmastoid approach

\section{Background}

Aural atresia is a rare condition present at birth, which was estimated to be $1: 10,000$ to $1: 20,000[1,2]$. The condition is associated with microtia. Congenital aural atresia may be isolated, a part of syndrome, or chromosomal aberration. Aural atresia mostly affect the right side, osseous more than membranous, and is found in male more than female 3-5 times. On embryological bases, the inner ear is usually normal $[3,4]$. This is the basis for repair of aural atresia. The atresia have cosmetically

Correspondence: essament2014@gmail.com

Ear, Nose and Throat Department, Hearing and Speech Institute, General Organization for Teaching Hospitals and Institutes, Giza, Egypt and functional impact on the patients, which is related to the disorder degree (partial or complete) or the extent (unilateral or bilateral).CAA have different grading system, the most applied one is The Jahrsdoerfer grading scale, which is based on preoperative CT scan and appearance of the auricle. These scales form the cornerstone for picking up the perfect patients for surgical correction of CAA. In addition to the grading system, another factor is the timing of surgery depending on the age of the patient better at the age of 4 or 5 years for better mastoid pneumatization but early bone surgery on one ear at 2 years of age is advised in bilateral cases, unilateral atresiaplasty is typically postponed until $15-16$
SpringerOpen (c) The Author(s). 2021 Open Access This article is licensed under a Creative Commons Attribution 4.0 International License, which permits use, sharing, adaptation, distribution and reproduction in any medium or format, as long as you give appropriate credit to the original author(s) and the source, provide a link to the Creative Commons licence, and indicate if changes were made. The images or other third party material in this article are included in the article's Creative Commons licence, unless indicated otherwise in a credit line to the material. If material is not included in the article's Creative Commons licence and your intended use is not permitted by statutory regulation or exceeds the permitted use, you will need to obtain permission directly from the copyright holder. To view a copy of this licence, visit http://creativecommons.org/licenses/by/4.0/. 
years of age, but we prefer to do so sooner despite intact contralateral hearing, as these patients have difficulties in communication and academic performance $[5,6]$. Either audiometric or ABR must be performed to establish cochlear function and imaging of temporal bone must be done to assess the inner ear. Correction of aural atresia is known, as one of the most difficult otologic surgery. The benefits from the surgery must exceed the risks largely. Hazards in surgery, such as facial nerve damage, membranous labyrinthitis, postoperative canal stenosis, infections, and induced sensory neural hearing loss caused by transmission of drill vibration $[7,8]$, have been prevented by routine use of CT scan and facial nerve monitoring [9]. Repair of CAA is a complex procedure, so high resolution CT scan is vital preoperatively to delineate and evaluate the facial nerve course, which is most likely aberrant, and also evaluate the atresia plate, the mandibular condyle, the width of the tympanic cavity, the ossicular chain, the inner ear, the fenestra, sigmoid sinus, and mastoid pneumatization is important as well as for the presence of cholesteatoma [10]. Typical inner ear, normal ossicles, well-developed middle ear, and normal Eustachian canal are ideal candidates for surgical repair [11]. However, in our research, we included patients with limited middle ear space and deformed or missing ossicles and cases with irregular direction of the facial nerve.

\section{Methods}

The Ethics Committee of the Research Center has approved the thesis and all participants have completed informed consent. For this non-randomized controlled sample, each of the 16 procedures was considered an individual case, and each procedure was considered his or her control. The research was completed at the Hearing and Speech Institute from 2014 to 2018. The cases with incomplete atresia or soft tissue atresia have been excluded. The study was composed of 16 patients, 8 patients for each group, 10 males and 6 females ranging from 4 to 18 years with a median age of 6 years. Ten of the patients had bilateral atresia and six patient's unilateral atresia. Pure tone audiometry following complete and comprehensive physical exams, ABR, and temporal bone high-resolution CT scan was obtained for all cases. Patients with unilateral or bilateral CAA and Jahrsdoerfer ratings of six or more were found to be eligible for surgical repair as in Fig. 1. PTA follow-up was collected 3 and 12 months post-operatively. Mean air-bone gap (ABG) of $500,1000,2000$, and $4000 \mathrm{~Hz}$ were evaluated preand post-operatively. Both groups were monitored for 12 months to assess problems such as bone canal stenosis, facial nerve impairment, sensorineural hearing loss, granulation tissue development, graft lateralization, wound dehiscence, ossicular fixation, and prosthesis extrusion, otorrhea, tympanic membrane perforation, and cholesteatoma. Hearing success was described as $\mathrm{ABG}$ below $30 \mathrm{~dB}$ and was able to communicate post-operatively without the use of hearing aids.

\section{Surgical procedure}

At the start of the surgery, 0.008-in break thickness is obtained from the inner side of the upper ipsilateral thigh by grafting the skin with a dermatome. The graft, dermis side up, was applied on the occlusive gauze, and slices of $1 \times 5 \mathrm{~cm}$ are created, set a side, and kept moist. One surgeon did the procedures; the approaches were the same, postauricular incision of skin, the periostium elevated exposing a wide area of bone posterior to TMJ exposed for wide drilling.

\section{The transmastoid approach}

The drilling in the posterior superior direction from TMJ anterior to the posterior border of the mastoid parallel to the dural palate, inferiorly to the sigmoid sinus, the atretic plate would be removed. Continue drill deeply to widen the cavity so continue and continue inferior until the hypotympanum, anteriorly until the Eustachian tube, continue drilling posteriorly to the lateral and posterior semicircular canals and deep to the level of the semicircular canals at the sinodural angle. Mastoid saucerization may further reduce the risk of bone stenosis.

\section{The mastoid approach}

The drilling start directly posterior to TMJ, limited superiorly to the dural plate. This supposed to lie over the epitympanum. The drill done down until the atretic plate reached, as it fused with the malleus and the incus. Diamond burr used at this stage to make the atretic plate a thin paper sheet then removed by hook. Continue drilling down to the hypotympanum, anteriorly to the Eustachian tube, posteriorly to the level of facial nerve deep to the pyramid. After that point, in both technique, the assessment of the ossicular chain mobility, if intact and fully mobile, nothing is done, but in certain situations, the ossicles were absent or defective and the mobility of the ossicular chain was at issue, restoration with PORP/TORP was preferred which is titanium in nature, but in most cases the chain of the ossicles was mobile, although deformed. The new channel was circumferentially lined with the skin. Take note that the zigzag tips partly overlap the fascia without burying the skin beneath each other. The antibiotic-soaked scale wrapping preserved the skin grafting, which were kept for 2 weeks (Fig. 2). 


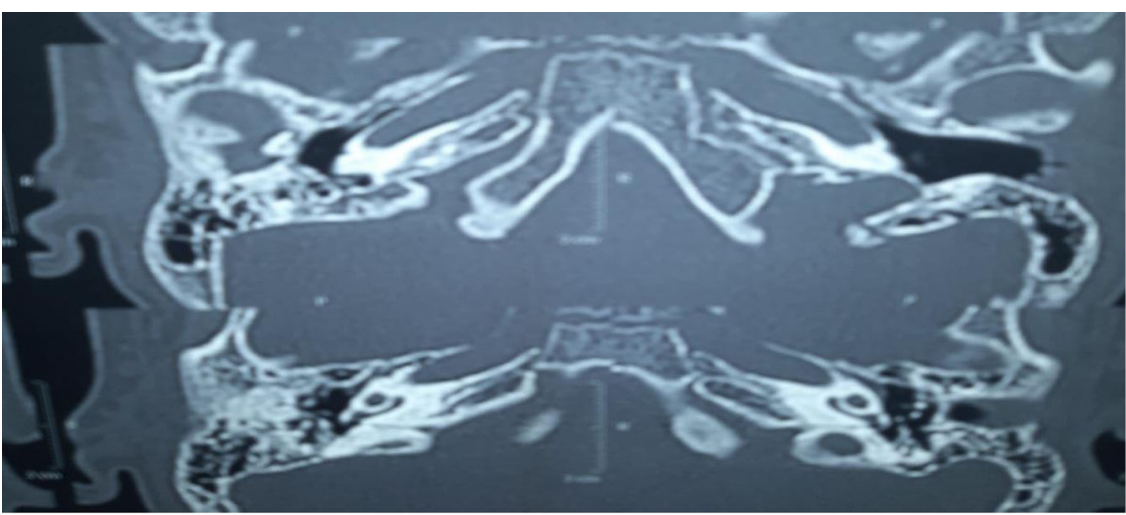

A; axial image of CT scan temporal bone show right aural atresia with good pnumatization of the middle ear

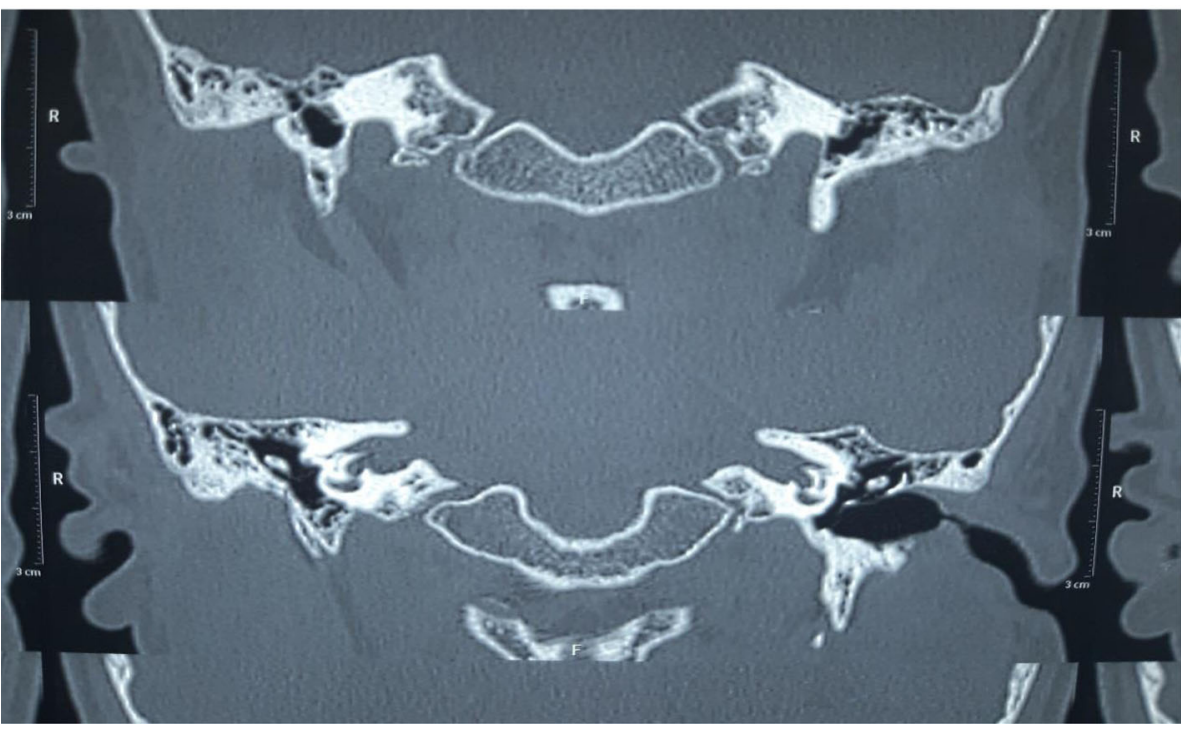

$\mathrm{B}$; coronal image of CT scan temporal bone show right aural atresia with good pnumatization of the middle ear and the ossicles

Fig. 1 CT scan, coronal and axial view show atresia of the right ear. A Axial image of CT scan temporal bone shows right aural atresia with good pneumatization of the middle ear. B Coronal image of CT scan temporal bone show right aural atresia with good pneumatization of the middle ear and the ossicles

\section{Surgical findings}

In four patients (25\%), malleus was deformed, fixed in four (25\%), and appeared normal in eight cases (50\%). The incus deformed in six cases (37.5\%), fixed in two (12.5\%), and appeared normal in eight patients (50\%). Stapes were usual in 13 patients $(81.25 \%)$, and deformed in three patients $(18.75 \%)$. In five cases, ossicle chain reconstruction was performed (31.25\%). Stapedectomy for the placement of the TORP was performed in two cases done as the usual stapedectomy done by fenestration of the footplate of the two cases. We use PORP in three cases, with one case where the incus is incomplete and two case where the incus is markedly deformed. In 14 cases $(87.5 \%)$, the facial nerve was in its usual location, partially overlapping the footplate in two cases $(12.5 \%)$. We continued with surgery even in cases where the facial nerve was partially overlapping the footplate. In all cases, the oval window was clear, and in two cases, we did not find an apparent round window (12.5\%). Cholesteatoma was detected intraoperatively in two patients.

\section{Results}

The air-bone gap increased from the preoperative mean of both classes' anterior mastoid and transmastoid from $48 \mathrm{~dB}, 49 \mathrm{~dB}$ to $24 \mathrm{~dB}$, and $25 \mathrm{~dB}$, retrospectively, 3 months postoperatively. When all patients were 


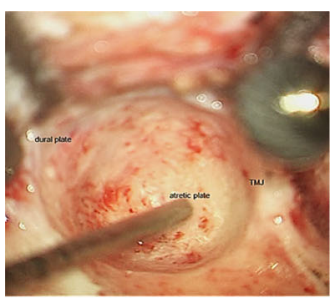

(A); drilling through atelectatic plate marked anteriorly by TMJ, superiorly by dural plate

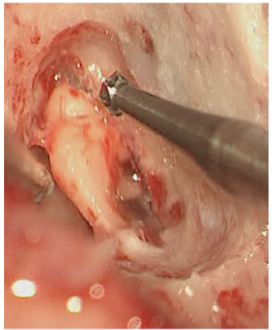

(B); freeing the malleo-incudal fold from the atelectatic plate

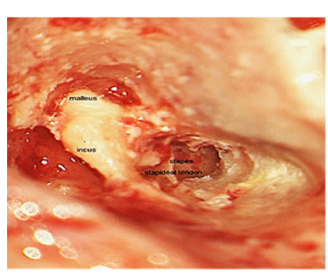

(C); after complete drilling of the atelectatic plate, head of malleus, incus, stapes, stapedia tendon, and the facial nerve all these structures are clear

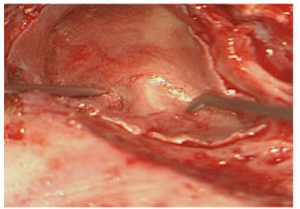

(D); temporalies fascia graft over the ossicles

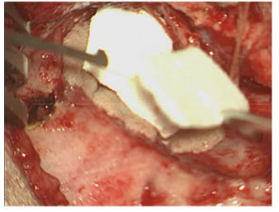

(E); TERSCH graft over the fascia then gelfoam

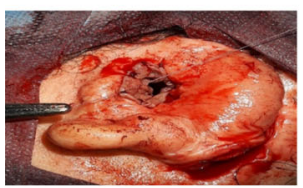

(F); TERSCH graft sutured to the skin of the auricle

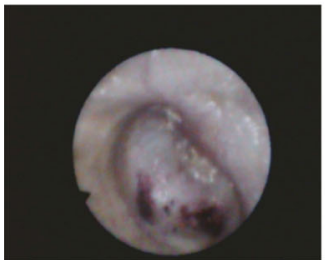

(g); Six-month postoperative show intact tympanic membrane, wide external auditory cana
Fig. 2 The right ear (A, B, C, D, E, F, G) shows the steps of anterior mastoid approach for aural atresia repair. A Drilling through atelectatic plate marked anteriorly by TMJ, superiorly by dural plate. B Freeing the malleo-incudal fold from the atelectatic plate. C After complete drilling of the atelectatic plate, head of malleus, incus, stapes, stapedial tendon, and the facial nerve; all these structures are clear. D Temporalies fascia graft over the ossicles. E TERSCH graft over the fascia then gelfoam. $\mathbf{F}$ TERSCH graft sutured to the skin of the auricle. $\mathbf{G}$ Six-month postoperative show intact tympanic membrane, wide external auditory canal

considered, the 12-month long-term postoperative ABG was $30 \mathrm{~dB}, 35 \mathrm{~dB}$ retrospectively. The mean preoperative $A B G$ was comparable between the two classes ( $\mathrm{P}$ value 0.198 ), whereas 12 months postoperative ABG was higher in patients with anterior mastoid methods ( $\mathrm{P}$ value 0.001). Both groups benefit from surgery. Four patients (25\%) developed soft tissue stenosis, 2 patients in each group. There were no cases of stenosis in the bony canal. TM perforation was found in two patients (12.5\%), one patient in each group. Lateralization of the graft was seen in one patient in the transmastoid group and no ossicular chain refixation was found. Five cases had postoperative otorrhea, one in the anterior mastoid group, and four in the transmastoid group, which were successfully treated with steroid and antibiotic drops. There have been no cases of facial nerve palsy, acquired cholesteatoma, extrusion of the prosthesis, sensorineural hearing loss, or wound dehiscence after surgery (Table 1$)$.

\section{Discussion}

Proper scheduling and choice of surgical approach are contentious. An exceptional hearing result after atresiaplasty is the most desirable outcome possible. The economic situation in the local area affects the management planning, although hearing results are excellent with BAHA, surgical restoration is still less expensive than BAHA. As the chances of injuries such as facial nerve damage, meatal stenosis, and grafting failure are too high for surgery, but still careful selection of patients can achieve the highest success rate. Occult cholesteatoma cases are compulsory for surgery. A fair requirement of satisfactory procedure for bilateral atresia is one that eliminates the need for hearing aid; while in the case of unilateral atresia, successful surgery can largely remove the handicap of unilateral hearing loss; those conditions tend to be fulfilled if the hearing level is between 20 and $25 \mathrm{~dB}$ or better. In this study, there were 16 cases of CAA; there were two cases (12.5\%) of secret cholesteatoma that were destined to build future complications due to expansion and erosion if not been found and eliminated. In four cases (25\%), two cases of postoperative stenosis of the meatus of each category are deemed 
Table 1 Results of anterior mastoid and transmastoid approaches

\begin{tabular}{|c|c|c|c|c|c|c|}
\hline \multirow{2}{*}{$\begin{array}{l}\text { Patients } \\
\text { No. }\end{array}$} & \multicolumn{3}{|c|}{ Anterior mastoid group } & \multicolumn{3}{|c|}{ Transmastoid group } \\
\hline & Preop. PTA & Postop. PTA & Complication & Preop. PTA & Postop. PTA & Complication \\
\hline 1 & 50 & 16 & & 48 & 18 & \\
\hline 2 & 55 & 25 & & 54 & 25 & Infection \\
\hline 3 & 40 & 18 & & 56 & 27 & Infection \\
\hline 4 & 45 & 27 & Stenosis & 58 & 36 & Infection, failed graft \\
\hline 5 & 38 & 23 & Infection & 40 & 22 & \\
\hline 6 & 62 & 22 & & 45 & 26 & Stenosis \\
\hline 7 & 45 & 35 & Stenosis & 42 & 25 & Infection, graft lateralization \\
\hline 8 & 50 & 26 & Failed graft & 47 & 23 & Stenosis \\
\hline Average & 48 & 24 & & 49 & 25 & \\
\hline
\end{tabular}

a mild problem because a comparatively straightforward operation may be done to correct this lateral stenosis. Stenting materials are not used because the procedures mentioned here are likely to stimulate rather than prevent cicatricial constrictions. The middle ear is approached anterosuperiorly; this site is as far as possible from a potential abnormally placed facial nerve. In this series, the facial nerve was neither encountered nor was there any postoperative facial weakness. The mastoid technique has been well defined and is still being used by some surgeons. However, this procedure leaves a large mastoid cavity with a potential for deposition of debris and otorrhea if any residual mucosa or granulation tissue persists in the cavity [12]. The tympanic membrane graft lateralization is a frequent cause of failure of this technique [5]. Although the improvements of hearing with this procedure are greater than those obtained with the mastoidectomy method, the purpose of consistently achieving successful hearing results remains elusive. Similar to other series [13, 14], a reasonably high rate of complications are registered (25\%). Notably, most of these complications have been conservatively resolved and all have had limited health results. Soft-tissue stenosis (25\%) for each group and TM lateralization (12.5\%) for transmastoid approach occurred relatively infrequently. TM lateralization rate improved in the presenting study, which was $18 \%$ in a previous publication [14]. TM perforation rate of $12.5 \%$ in each category is compatible with most other studies [15, 16]. The incidence of soft-tissue stenosis (25\%) is consistent with the previous series [17] and other publications $[15,18]$. However, several other studies $[16,19]$ have cited this complication at slightly higher rates of $30 \%$. These findings show that the anterior mastoid is more successful than the transmastoid one.

\section{Conclusion}

In conclusion, congenital ear atresia surgery can be made healthy and rewarding by successful case selection, careful preoperative examination, review using radio imaging, and if the surgery is performed by an experienced surgeon. The anterior mastoid technique is relatively secure with limited ossicular mass manipulation and the mastoid cavity problems can be avoided. In most cases, the facial nerve is expected to be atypical also; the stapes is expected to be mobile in the majority of the cases. Finally, postoperative follow-up is almost as critical as the surgical procedure. Early identification of meatal narrowing can be handled by dilation and can be sustained over a span of several months without effective reoperation. Both the grading scale and the anterior surgical approach are highly indicated for all the otologic surgeons performing atresiaplasty.

\section{Abbreviations \\ CAA: Congenital aural atresia; A-BG: Air bone gap; DB: Decibel; PTA: Pure tone audiogram; TORP: Total ossicular prosthesis reconstruction; PORP: Partial ossicular prosthesis reconstruction; TMJ: Tempromandibular joint; \\ $\mathrm{CT}$ : Computerized tomography}

\section{Acknowledgements \\ None}

Author's contributions

EF analyzed and interpreted the patient data regarding the selection and the surgical intervention. EF performed the radiological examination of the ear, and was a major contributor in writing the manuscript. The author read and approved the final manuscript.

\section{Funding \\ None}

\section{Availability of data and materials}

The datasets used and/or analyzed in the current study are available from the corresponding author on reasonable request. 


\section{Declarations}

\section{Ethics approval and consent to participate}

The Ethics Committee of the Research Center has approved the thesis; the study adhered to the tenets of the Declaration of Helsinki. Informed written consent to participate in the study was obtained by all participants (or their parent or legal guardian in the case of children under 16). Local ethics committee approved no number available, the consent obtained from the Ear, Nose and Throat Department, Hearing and Speech Institute, General Organization for Teaching Hospitals and Institutes, Egypt.

\section{Consent for publication}

Written informed consent was obtained from a parent or legal guardian of participants under 16 years old for publication.

\section{Competing interests}

The author declares that he has no competing interests.

Received: 20 January 2021 Accepted: 16 April 2021

Published online: 23 August 2021

\section{References}

1. Kelley PE, Scholes MA (2007) Microtia and congenital aural atresia. Otolaryngol Clin North Am 40(1):61-80. https://doi.org/10.1016/j.otc.2006.10. 003

2. El-Begermy MA, Mansour Ol, El-Makhzangy AMN, El-Gindy TS (2009) Congenital auditory meatal atresia: a numerical review. Eur Arch Otorhinolaryngol 266(4):501-506. https://doi.org/10.1007/s00405-008-0783-9

3. Bouhabel S, Arcand P, Saliba I (2012) Congenital aural atresia: boneanchored hearing aid vs. external auditory canal reconstruction. Int J Pediatr Otorhinolaryngol 76(2):272-277. https://doi.org/10.1016/j.jporl.2011.11.020

4. Siegert R, Mattheis S, Kasic J (2007) Fully implantable hearing aids in patients with congenital auricular atresia. Laryngoscope 117(2):336-340. https://doi.org/10.1097/MLG.0b013e31802b6561

5. De la Cruz A, Linthicum FH Jr, Luxford WM (1985) Congenital atresia of the external auditory canal. Laryngoscope 95(4):421-427

6. Jahrsdoerfer RA, Yeakley JW, Aguilar EA et al (1982) Grading system for the selection of patients with congenital aural atresia. Am J Otol 13:6-12

7. Curtin HD (1988) Congenital malformations of the ear. Otolaryngol Clin North Am 21(2):317-336. https://doi.org/10.1016/S0030-6665(20)31541-3

8. Mehra YN, Dubey SP, Mann SBS (1988) Correlation between high resolutions computerised tomography and surgical findings in congenital aural atresia. Arch Otolaryngol Head Neck Surg 114:131-141

9. Linstrom CJ, Meitles LZ (1993) Facial nerve monitoring in surgery for congenital auricular atresia. Laryngoscope 103(4 Pt 1):406-415. https://doi. org/10.1002/lary.5541030408

10. Manolopoulos L, Papacharalampous GX (2010) Congenital aural atresia reconstruction: a surgical procedure with a long history. J Plast Reconstr Aesthet Surg 63:774-781

11. Alarcon AD, Choo DI (2007) Controversies in aural atresia repair. Curr Opin Otolaryngol Head Neck Surg 15(5):310-314. https://doi.org/10.1097/MOO. 0b013e3282f005d2

12. Fenner T, Wachter I, Fisch U (1982) Atresia auris congentita: Probleme und Resultate der operativen Therapie. ORL 5:186-192

13. Li C, Zhang T, Fu Y, Qing F, Chi F (2014) Congenital aural atresia and stenosis: surgery strategies and long-term results. Int J Audiol 53(7):476-481. https://doi.org/10.3109/14992027.2014.890295

14. El-Hoshy Z, Abdel-Aziz M, Shabana M (2008) Congenital aural atresia: transmastoid approach; an old technique with good results. Int J Pediat Otorhinolaryngol 72(7):1047-1052. https://doi.org/10.1016/j.ijporl.2008.03.011

15. De la Cruz A, Teufert KB (2003) Congenital aural atresia surgery: long-term results. Otolaryngol Head Neck Surg 129(1):121-127. https:/doi.org/10.1016/ S0194-5998(03)00531-X

16. Shih L, Crabtree JA (1993) Long-term surgical results for congenital aural atresia. Laryngoscope 103(10):1097-1102. https://doi.org/10.1288/0000553 7-199310000-00004

17. Digoy GP, Cueva RA (2007) Congenital aural atresia: review of short- and long-term surgical results. Otol Neurotol 28(1):54-60. https://doi.org/10.1 097/01.mao.0000227897.73032.95

18. Chandrasekhar SS, De la Cruz A, Garrido E (1952) Surgery of congenital aural atresia. Am J Otol 16(6):713-717
19. Nishizaki K, Masuda Y, Karita K (1999) Surgical management and its postoperative complications in congenital aural atresia. Acta Otolaryngol Suppl 540:42-44

\section{Publisher's Note}

Springer Nature remains neutral with regard to jurisdictional claims in published maps and institutional affiliations.

\section{Submit your manuscript to a SpringerOpen ${ }^{\circ}$ journal and benefit from:}

- Convenient online submission

- Rigorous peer review

- Open access: articles freely available online

High visibility within the field

- Retaining the copyright to your article

Submit your next manuscript at $\boldsymbol{\nabla}$ springeropen.com 